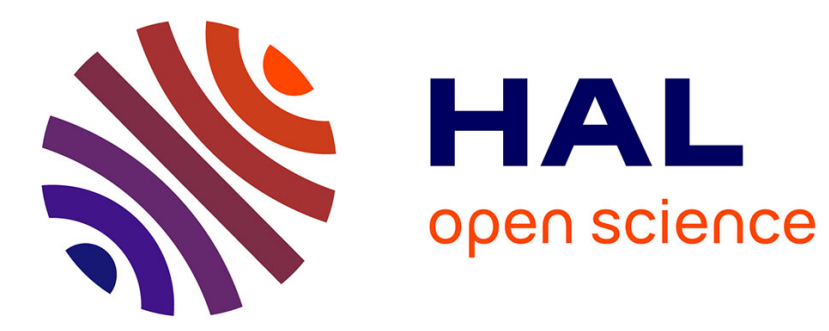

\title{
Ionic Liquids as Extraction Media in a Two-Step Eco-Friendly Process for Selective Tantalum Recovery
}

Cyril Micheau, Guilhem Arrachart, Raphael Turgis, Manuel Lejeune, Micheline Draye, Stéphanie Michel, Sophie Legeai, S Pellet-Rostaing

\section{- To cite this version:}

Cyril Micheau, Guilhem Arrachart, Raphael Turgis, Manuel Lejeune, Micheline Draye, et al.. Ionic Liquids as Extraction Media in a Two-Step Eco-Friendly Process for Selective Tantalum Recovery. ACS Sustainable Chemistry \& Engineering, 2020, 8 (4), pp.1954-1963. 10.1021/acssuschemeng.9b06414 . hal-03084410

\author{
HAL Id: hal-03084410 \\ https://hal.science/hal-03084410
}

Submitted on 5 Jan 2021

HAL is a multi-disciplinary open access archive for the deposit and dissemination of scientific research documents, whether they are published or not. The documents may come from teaching and research institutions in France or abroad, or from public or private research centers.
L'archive ouverte pluridisciplinaire HAL, est destinée au dépôt et à la diffusion de documents scientifiques de niveau recherche, publiés ou non, émanant des établissements d'enseignement et de recherche français ou étrangers, des laboratoires publics ou privés. 


\section{Ionic liquids as extraction media in a two-steps eco-friendly process for selective Tantalum recovery}

Cyril Micheau ${ }^{a}$, Guilhem Arrachart ${ }^{a}$, Raphael Turgis ${ }^{a}$, Manuel Lejeune $^{b}$, Micheline Draye ${ }^{b}$, Stéphanie Michel ${ }^{c}$, Sophie Legeaic, Stéphane Pellet-Rostaing ${ }^{a}$

a ICSM, Univ Montpellier, CEA, CNRS, ENSCM, Marcoule, France

b LCME, Univ Savoie Mont Blanc, Le Bourget du Lac, France

c IJL-UMR CNRS 7198, Univ Lorraine, Groupe Chimie et Electrochimie des Matériaux, Metz, France

Corresponding author: guilhem.arrachart@cea.fr

\section{Abstract}

The unique properties of tantalum (Ta) have resulted in its important usage to supply the capacitors and semiconductor production for electronics devices. Technological needs make Ta economically and strategically important to industrialized countries. Among different possibilities, the recovery of Ta from industrial waste and end-of-life products represents an economically attractive and viable approach, which aims at decreasing the environmental footprint in general. Currently, there is a lack of an efficient Ta recycling strategy from e-waste.

In the present work we studied the possibility to use pure ionic liquids such as $N$-butyl- $N$-ethylpiperidinium bis(trifluoromethylsulfonyl)imide (EBPiP-NTf $f_{2}$ ), N-octyl-N-ethyl-piperidinium bis(trifluoromethylsulfonyl)imide (EOPiP-NTf ${ }_{2}$ ) as extracting media. Ionic liquids were used as alternative solvents that will have limited impact on health and environment compared to traditional organic solvents.

We propose an eco-friendly process for the extraction and stripping of tantalum from sulfuric acidic medium that may come from of the dissolution of bottom ash and by-products of industrial activities, as well as from secondary sources such as waste electrical and electronic equipment (WEEE). The extractability of ILs for Ta was demonstrated, and under the experimental conditions, the more promising properties have been highlighted for EOPiP-NTf 2 . Back extraction of Ta from the loaded ionic liquid phase was also examined and showed that quantitative recovery of metal was possible using water, allowing thus to recover the ionic liquid and the Ta.

Considering the efficiency as well as greener aspects of the process, due to the use of ionic liquids which loss is highly limited in aqueous phase, a more "sustainable process" is proposed in comparison to organic solvents and previous ionic liquid based extraction system useful for the selective recovery of tantalum.

\section{Keywords}

tantalum; ionic liquids; separation; recovery; recycling; eco-friendly extraction process 


\section{Introduction}

The importance of valuable metals involved in most of the high technology devices in the global economy is growing due to the high demand. The importance and shortage for such metals lead them to be regarded as critical and/or strategic. ${ }^{1}$ It is therefore necessary to find alternative sources of supply. Metal prospection/mining efforts have been intensified in this regard and their extraction and valorization in particular through recycling are increasingly considered. Indeed, even if metal mining has significant economical benefits, it has been shown to cause persistent environmental devastations. ${ }^{2}$ Thus, recycling of materials from end-of-life product is the main pillars of the circular economy, it saves and reduces the need of primary raw materials decreasing the environmental footprint in general. ${ }^{3}$

The growth of "urban mines" motivates a variety of research that pointed out the relevance of waste electrical and electronic equipment (WEEE, or e-waste) as a source of valuable metals. ${ }^{4-7}$ The recycling of such metals from "urban mines" has become essential, however, their operation is at the moment still inefficient. ${ }^{8}$ Furthermore, printed circuit boards (PCBs) represent only $3 \%$ to $6 \%$ of the total mass of e-waste, but they contain large quantities of metal of interest. ${ }^{8,9} \mathrm{~A}$ typical PCB consists of more than twenty different types of metals, ${ }^{10}$ including precious ones (e.g. gold, silver and platinum), base (e.g. copper, aluminium and steel) as well as some strategic metals such as tantalum (Ta), which are not considered enough. ${ }^{11}$ Tantalum has high economic importance and play an essential role in our everyday life attributed to its widely use in electronic devices mainly in the form of tantalum capacitors. ${ }^{12}$ Efforts to recycle this element from manufacturing scrap has been made, ${ }^{13,14}$ however the current end-of-life recycling rate of Ta is less than $1 \%$ and a circular economy has not been established for this metal. ${ }^{15-17}$ Ueberschaar et al. show the interest and limitation of Ta recycling by doing a complete characteristics study of tantalum capacitors including the average tantalum content per mass of PCB. ${ }^{17}$

The extraction and refining of tantalum, including its separation from niobium in the various tantalumcontaining solutions have been performed thanks to hydrometallurgical processes. Thus, a variety of organic solvents such as methyl iso-butyl ketone (MIBK), tri-butyl phosphate (TBP), cyclohexane and 2-octanol have been used for tantalum and niobium separation either from other impurities or from each other. ${ }^{18}$ One of the key area of green chemistry is the elimination or replacement of hazardous solvents in terms of toxicity and flammability, which has a clear impact on worker safety and environmental issue. In regards to the use of such organic solvents, eco-friendly alternative and highly efficient process for tantalum separation and recovery must be developed.

Room-temperature ionic liquids (ILs), due to their quasi non flammability and non volatility, are already used as alternative diluents or extractants of volatile organic compounds in extraction processes. ${ }^{19,20}$ Recently, various IL-based extraction systems for metal ions separation have been investigated showing their potential for the development of "greener" processes. ${ }^{21-24}$

Ionic liquid composed of Lewis acid mixtures of di-alkyl imidazolium halides and aluminum chloride have been used to dissolve all components of a capacitor except the tantalum anode which has been mechanically separated and suitable for further metallurgical processing. ${ }^{25}$ Recently we have demonstrated the possibility of using ketone or phosphonate functionalized task specific ionic liquids (TSILs) for the selective extraction of tantalum from sulfuric acid medium as an alternative to the MIBK or TBP. ${ }^{26,27}$ Indeed, the extraction behavior of Ta with TSIL was suggested to be most effective than conventional organic solvent, with a high selectivity for $\mathrm{Ta}$ in regards to competitive elements 
contained in the capacitor leaching solution. Also, the recovery of Ta after extraction and the recyclability of the TSIL have been demonstrated.

However, such TSIL are still not commercially available due to their synthesis cost at industrial scale, and their use can be limited before developing a commercially viable process for Ta-recovery.

Here, we report systematic studies on the solvent extraction process for the recovery of Ta from a sulfuric medium using two ILs combining piperidinium (PiP) cations and the bis(trifluoromethylsulfonyl)imide ( $\mathrm{NTf}_{2}$ ) anion, an association that lead to hydrophobic ILs as $\mathrm{N}$-butyl$\mathrm{N}$-ethyl-piperidinium bis(trifluoromethylsulfonyl)imide (EBPiP-NTf ${ }_{2}$ ) and $\mathrm{N}$-octyl- $\mathrm{N}$-ethyl-piperidinium bis(trifluoromethylsulfonyl)imide (EOPiP-NTf ${ }_{2}$ ) (Table 1). Previous studies involving task specific ionic liquids highlighted that piperidinium cation exhibit good extraction and stripping efficiencies in regard to other cation such as tributylamamonium, methylimidazolium, pyridinium or methylpyrrolidinium. ${ }^{26,}$ 27.

Such ILs are obtained from commercially available bromo-alkanes which are reacted with 1ethylpiperidine. First generation's IL is then submitted to metathesis with LiNTf $f_{2}$ leading to a second generation IL more easily accessible than the ketone or phosphonate TSILs previously used in tantalum extraction.. ${ }^{25,26}$ Due to up-front costs associated with their preparation, the synthesis pathway also impacts their green chemistry. For example, the E-factor which is evaluated $>3$ for ketone or

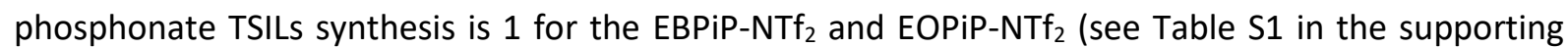
information which summarizes several metrics used for evaluation of the greenness of ILS and TSILS syntheses).

The principal aim of this present research was to propose an eco-friendly process for the extraction and stripping of tantalum from sulfuric acidic media, using commercially available ionic liquids.

The performances of two ILs, EBPiP-NTf $f_{2}$ or EOPiP-NTf $f_{2}$ for the extraction of Ta are considered in detail, and the recycling of the IL phase is investigated in a series of extraction-stripping cycles. In addition, precipitation and calcination step performed after the stripping of Ta from loaded ILs ultimately allows recovering the Ta in its oxide form.

Table 1. Structure and physico-chemical properties of $N$-butyl- $N$-ethyl-piperidinium bis(trifluoromethylsulfonyl)imide (EBPiP$\mathrm{NTf}_{2}$ ) and $\mathrm{N}$-octyl- $N$-ethyl-piperidinium bis(trifluoromethylsulfonyl)imide (EOPiP-NTf 2 ).

\begin{tabular}{|c|c|c|c|c|c|}
\hline IL structure & $\begin{array}{c}\text { Molecular } \\
\text { weight } \\
\text { (g/mol) }\end{array}$ & Purity & $\begin{array}{c}\text { Density } \\
\left(\mathrm{g} / \mathrm{cm}^{3}\right) \\
20^{\circ} \mathrm{C}\end{array}$ & $\begin{array}{c}\text { Viscosity } \\
\text { (mPa.s) } \\
20^{\circ} \mathrm{C}\end{array}$ & $\begin{array}{c}\text { Water } \\
\text { content (\%) }\end{array}$ \\
\hline $\begin{array}{l}\text { EBPip-NTf }_{2} \\
\left\langle{ }_{\oplus}{ }^{\ominus}{ }_{\mathrm{NTf}_{2}}\right.\end{array}$ & 450.46 & $\geq 98 \%$ & 1.3659 & 284 & 0.025 \\
\hline$\overbrace{\oplus}^{\text {EOPip-NTf }}{ }^{{ }_{2}}{ }_{\mathrm{NTf}_{2}}$ & 506.57 & $\geq 98 \%$ & 1.2734 & 406 & 0.095 \\
\hline
\end{tabular}




\section{Materials and methods}

\section{Materials and reagents}

The ionic liquids $N$-butyl- $N$-ethylpiperidinium bis(trifluoromethylsulfonyl)imide [EBPip][NTf2] and $\mathrm{N}$-octyl- $\mathrm{N}$-ethylpiperidinium bis(trifluoromethylsulfonyl)imide [EOPip][NTf2] were synthesized according to the literature ${ }^{28}$ or supplied by Solvionic (France) when large quantities were needed. Their physico-chemical properties are summarized in Table 1.

The density measurements were performed with a DSA 5000 thermo-regulated digital densimeter (Anton Paar). The apparatus measures densities using an oscillating U-tube with an accuracy of $0.00001 \mathrm{~g} / \mathrm{cm}^{3}$ and temperature controlled to within $0.001{ }^{\circ} \mathrm{C}$. All measurements were conducted at $25.005 \pm 0.004{ }^{\circ} \mathrm{C}$.

For the viscosity measurements, an RM 200 Lamy rheometer with a CP-400 cone plate system was used. A plate-plate geometry (PP25, diameter 24.981) was chosen to measure shear viscosities under thermostatic control $\left(25^{\circ} \mathrm{C}\right)$ from shear rates of 0.1 to $3001 / \mathrm{s}$. Shear rates were increased with 10 point per decade. The measurement duration per point was set to $6 \mathrm{~s}$.

Acid concentration in the aqueous and IL phases before and after extraction was analyzed by titration with $\mathrm{NaOH} 0.1$ or $0.01 \mathrm{M}$ (Fluka analytical) using a Metrohm 809 Titrando.

The solubility of the IL in the aqueous phase was determined by measuring the concentrations of the cation in the aqueous solutions by determining the Total Organic Content (TOC) using a Shimadzu TOCVCSH analyzer based on a $680^{\circ} \mathrm{C}$ combustion catalytic oxidation/NDIR method.

The water content of ILs was determined by Karl Fischer coulometric titration using a Metrohm 831 KF Coulometer or a Metrohm 809 Titrando by titration with $\mathrm{Hydranal}^{\circledR}$ composite 2. The IL was contacted with the aqueous phase for $1 \mathrm{~h}$, and the two-phase system was then centrifuged and the IL water content was measured.

Metal concentrations were measured before and after extraction by inductively coupled plasma/atomic emission spectroscopy (ICP/AES) using a SPECTRO ARCOS spectrometer or Inductively Coupled Plasma Mass Spectrometry (ICP/MS) using a Thermo Scientific iCAP RQ instrument. Uncertainties relating to the metal concentration were determined by repeated measurement of different samples of the same concentration. These uncertainties were estimated to be of the order of $\pm 5 \%$.

Powder X-ray diffraction patterns were recorded on a Bruker D8 advance diffractometer using CuK $\alpha$ radiation $(\lambda=1.5418 \AA$ ). The data were collected in Bragg-Brentano geometry over $2 \theta$ range of $10^{\circ}-80^{\circ}$ with a step size of $0.015^{\circ}$. The crystallite size (L) was estimated from the line broadening of the XRD peaks using the Scherrer formula: $L=0.9 \lambda \beta \cos \theta$, where $\lambda$, is the wavelength of the X-rays; $\beta$, the full-width at half-maximum height (rad); and $\theta$, the diffraction angle.

SEM analyses were obtained with a TESCAN VEGA3 scanning electron microscope coupled with an EDX Bruker QUANTAX microanalyser.

\section{Extraction experiments}

$\mathrm{Ta}(\mathrm{V})$ stock solutions $(1-7 \mathrm{~g} / \mathrm{L})$ were prepared at the desired acidity $\left(\mathrm{H}_{2} \mathrm{SO}_{4} 0-9 \mathrm{M}\right)$ from $10000 \mathrm{mg} / \mathrm{L}$ or $30000 \mathrm{mg} / \mathrm{L} \mathrm{ICP}$ standard from SCP Science (aqueous solution of $\mathrm{NH}_{4} \mathrm{TaF}_{6}$ with $4 \%$ fluorhydric acid). A synthetic solution mimicking the capacitor leaching solution was prepared from $\mathrm{Ta}(\mathrm{V})$ and $\mathrm{Nb}(\mathrm{V})$, $10000 \mathrm{mg} / \mathrm{L}$ and $1000 \mathrm{mg} / \mathrm{L} \mathrm{ICP}$ standards and starting from metallic salt of $\mathrm{Fe}, \mathrm{Mn}, \mathrm{Ni}$ and $\mathrm{Ag}$. The desired concentrations were prepared by dilution using ultrapure water (Milli-Q, Millipore, $18 \mathrm{M} \Omega / \mathrm{cm}$ ) 
and the acidity was adjusted with sulfuric acid. The initial concentrations of metals were measured by ICP (ICP/AES or ICP/MS).

Extractions were performed by shaking $400 \mathrm{rpm}$ for $1 \mathrm{~h}$, defined volumes of IL and aqueous phases using a thermostated shaker (Infor-ht ${ }^{\circledR}$ ecotron) at $25^{\circ} \mathrm{C}$. Various aqueous to IL phase volumetric ratios $\left(V_{\mathrm{aq}} / \mathrm{V}_{\mathrm{IL}}\right)$ have been investigated. The aqueous and IL phases remained well separated, forming biphasic systems with any variation of volume phases after the extraction process.

After the extraction, phase separation was assisted by centrifugation (4000 rpm for $5 \mathrm{~min}$ ), and the aqueous phase was analyzed by ICP. The organic phase was submitted to a stripping step using ultrapure water (MilliQ, Millipore, $18 \mathrm{M} / / \mathrm{cm}$ ).

Stripping experiments were performed at $25^{\circ} \mathrm{C}$ by contacting the loaded IL phase with water during 1 $\mathrm{h}$ (aqueous to IL phase volumetric ratio $\mathrm{V}_{\mathrm{st}} / \mathrm{V}_{\mathrm{IL}}$ of 1,2 or 5 ). After separation by centrifugation (4000 rpm for $10 \mathrm{~min}$ ), metals concentrations were measured in the aqueous phase by ICP. All the experiments were carried out in duplicate measurements with a precision of $\pm 5 \%$.

The efficiency of the IL to selectively extract Ta from iron was evaluated from the following parameters. The distribution ratio (D) was determined using the following equation: $\mathrm{D}=[\mathrm{Ta}]_{\mathrm{IL}} /[\mathrm{Ta}]_{\mathrm{aq}}=\left(\mathrm{C}_{\mathrm{i}}-\mathrm{C}_{\mathrm{f}} / \mathrm{C}_{\mathrm{f}}\right) \times \mathrm{V}_{\mathrm{aq}} / \mathrm{V}_{\mathrm{IL}}$, where $\mathrm{Ci}$ and $\mathrm{Cf}$ are the concentrations of the metal ions in the aqueous phase before and after extraction, respectively. $V_{a q}$ is the volume of the aqueous phase and $V_{\mathrm{IL}}$ is the volume of the ionic liquid phase.

The extraction efficiency (\%E) was determined by using the following equation: \%E=(D / $(D+$ $\left.\left.\mathrm{V}_{\mathrm{aq}} / \mathrm{V}_{\mathrm{IL}}\right)\right) \times 100 \%$.

The stripping percentage (\%S) was calculated as follows $\% \mathrm{~S}=\left(\left([\mathrm{Ta}]_{\mathrm{st}} /[\mathrm{Ta}]_{\mathrm{IL}}\right) \times \mathrm{V}_{\mathrm{st}} / \mathrm{V}_{\mathrm{IL}}\right) \times 100 \%$, where $[\mathrm{Ta}]_{\mathrm{st}}$ and $[\mathrm{Ta}]_{\Perp L}$ are the concentrations of the metal ions in the stripping aqueous phase after stripping and the concentrations of the metal ions in the loaded ILs phase before stripping, respectively. The stripped TSIL phases were reused in further cycles of the extraction-stripping process.

The separation factor $\left(\mathrm{SF}_{\mathrm{Ta} / \mathrm{M}}\right)$ is given by: $\mathrm{SF}=\mathrm{D}_{\mathrm{Ta}} / \mathrm{D}_{\mathrm{M}}$, where $\mathrm{D}_{\mathrm{Ta}}$ and $\mathrm{D}_{\mathrm{M}}$ are the distribution ratios of the $\mathrm{Ta}$ and $\mathrm{M}$ the competitive ions, respectively.

The centrifugal mixer was kindly provided by the CEA/DMRC/SA2I/LGCI (homemade device). 


\section{Results and discussion}

\section{Study of the key parameters of the IL-based process Effect of $\mathrm{H}_{2} \mathrm{SO}_{4}$ concentration}

In a first set of experiments, the effect of $\mathrm{H}_{2} \mathrm{SO}_{4}$ concentration on the extraction behavior of tantalum using both ILs was investigated. The concentration of tantalum was fixed at 1 or $7 \mathrm{~g} / \mathrm{L}$ in the feed aqueous phase, while the $\mathrm{H}_{2} \mathrm{SO}_{4}$ concentration was varied over the range 0.1-9.0 mol/L.

Experiments were carried out with various $\mathrm{V}_{\mathrm{aq}} / \mathrm{V}_{\mathrm{IL}}$ ratios (1 or 5 ) thus modulating the amount of $\mathrm{Ta}$ in contact to the IL phase (all the experiments results are provided in the Supporting information see Figure SI-1).

Figure 1 represents the Ta extraction efficiency as function of sulfuric acid concentration for the most challenging conditions ( $\left.[\mathrm{Ta}]=7 \mathrm{~g} / \mathrm{L} \mathrm{Ta} ; \mathrm{V}_{\mathrm{aq}} / \mathrm{V}_{\mathrm{IL}}=5\right)$ and shows remarkable distribution ratio for both ILs $\left(D_{L I}>5\right)$. Ta extraction increases with the acidity of the aqueous solution, which is in accordance with the literature. ${ }^{18}$ For the EBPiP-NTf 2 , a maximum efficiency was obtained for a $6 \mathrm{M} \mathrm{H}_{2} \mathrm{SO}_{4}$ concentration as already observed with previous studies involving task specific ionic liquids. ${ }^{26,27}$

The ILs are efficient for the Ta extraction even at low acidity (extraction efficiency of Ta about $45 \%$ at $0.1 \mathrm{M} \mathrm{H}_{2} \mathrm{SO}_{4}$ ) compared to the literature where tantalum is not extracted at low acidity but only for sulfuric acid concentration higher than $3 \mathrm{M} .^{18}$

For both systems, it is possible to work over a wide range of acid concentrations even at $9 \mathrm{M}$ that is not the case for more classical extracting system like MIBK.

In order to provide a better comparison between both ILs, the following experiments were conducted at a concentration of $6 \mathrm{M}$ of sulfuric acid loaded with a $7 \mathrm{~g} / \mathrm{L}$ tantalum concentration using a volume ratio $V_{\text {aq }} / V_{\mathrm{IL}}=5$.

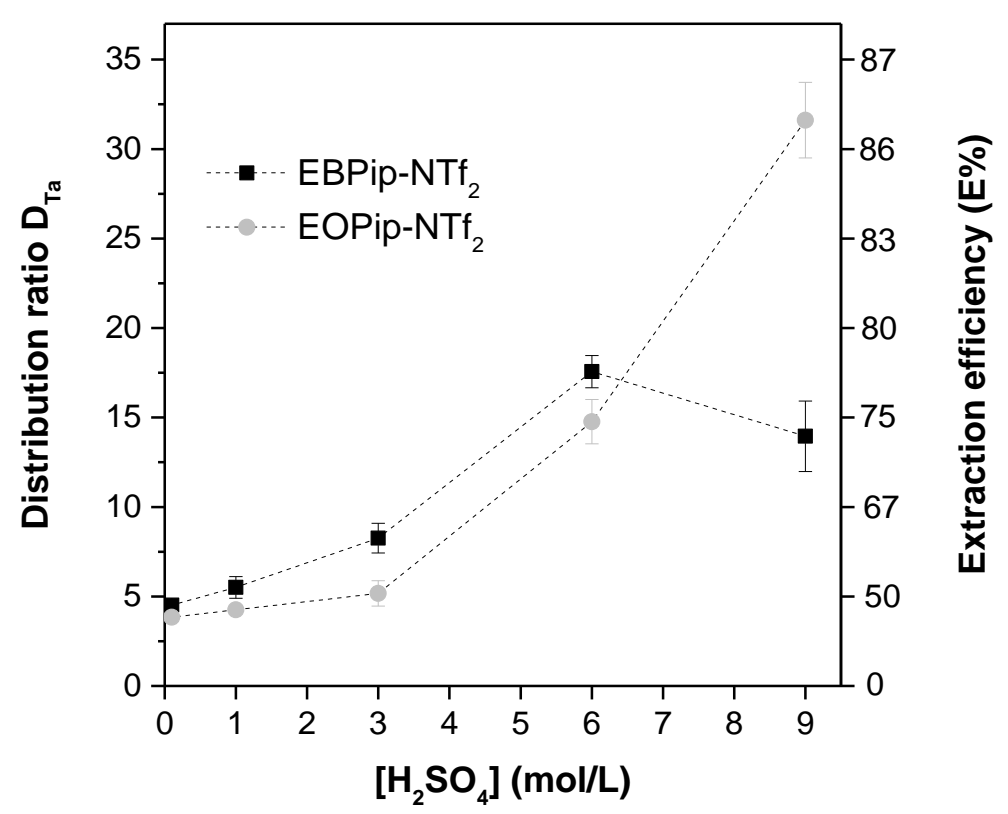

Figure 1. Distribution ratio and Extraction efficiency of Ta as a function of $\mathrm{H}_{2} \mathrm{SO}_{4}$ concentration. Extraction conditions: ILs phase: pure EBPiP-NTf $f_{2}$ or EOPiP-NTf $f_{2}$; Aqueous phase: $[\mathrm{Ta}]=7 \mathrm{~g} / \mathrm{L},\left[\mathrm{H}_{2} \mathrm{SO}_{4}\right]=0.1-9 \mathrm{M},[\mathrm{HF}]=1 \mathrm{M}$; $\mathrm{Vaq}_{\mathrm{alL}} / \mathrm{V} ; 1 \mathrm{~h}$ at $25^{\circ} \mathrm{C}$. 
It was reported in the literature that the alkyl chain length of the organic cation deeply affects the efficiency of extraction, particularly by changing the hydrophobicity of the IL. ${ }^{29-31}$ It has been shown that the extraction efficiency decreases as the hydrophobicity of the IL cation increases due to a lower IL partition / penetration in the aqueous phase, which limits the metal ion partitioning / transfer in the IL phase. The hydrophobicity property of the ILs have been studied confirming that the EOPip-NTf is $_{2}$ less transferred in the aqueous phase than the EBPip-NTf ${ }_{2}$. However, the results for the extraction of Ta obtained here for both ILs, EOPiP-NTf $f_{2}$ and EBPiP-NTf 2 , present a very similar trend, which suggests that the extraction efficiencies are not dependent on the hydrophobicity of IL cations in comparison to traditional IL-based extraction systems.

\section{Effect of equilibration time}

The contact duration required to reach the equilibrium of extraction is one of the crucial parameters. This duration is strongly influenced by hydrodynamic parameters such as viscosity that is one of the main drawbacks of IL for the development of IL-based process.

Both ILs are liquid at room temperature; they present a sufficiently low viscosity to be directly employed as pure extracting phase/extracting agents in liquid-liquid extraction experiments. In order to determine the equilibration time, a kinetic study for each IL was performed by varying the contact time between the aqueous phase and the extracting phase (see Figure S2 in Supporting Information). Despite their viscosity (see Table 1), the metal mass transfer from the aqueous phase to the IL phase is reached quickly.

The distribution ratio of Ta extraction reached a value between 15 and 18 (corresponding to an extraction efficiency about $75-80 \%$ of the initial Ta) after mixing for 5 and 10 minutes at $25^{\circ} \mathrm{C}$ for EBPiP$\mathrm{NTf}_{2}$ or EOPiP-NTf $f_{2}$ respectively, and remained almost constant thereafter. As a consequence it was assumed that it takes 10 minutes to reach the equilibrium state with both IL.

In order to ensure the complete extraction of the metal and establish a comparison, a contact time of 1 hour was consistently maintained in further experiments.

\section{Effect of temperature}

The increase of the temperature allows reducing the IL viscosity as illustrated in the Figure S3 (see Supporting Information). An increase of the temperature of 30 degrees allows dividing the viscosity by a factor 10. It can be expected that, this viscosity reduction should lead to an increase in the metal mass transfer from the aqueous phase to the IL phase. Figure 2 shows exhibits the Ta distribution ratio as function of temperature, from 20 to $60^{\circ} \mathrm{C}$, at $6 \mathrm{M} \mathrm{H}_{2} \mathrm{SO}_{4}$ with EBPiP-NTf $f_{2}$ and EOPiP-NTf 2 . The results show, despite the decrease of the viscosity of the IL phase, a decreasing of D-value with increasing the temperature. A change in viscosity would also impact on the kinetics of the extraction, but the equilibrium state is reached quickly so that this behavior was not highlighted.

These curves allow to determine the change in the enthalpy $(\Delta \mathrm{H})$ which can be calculated using the Van't Hoff relationship $\Delta H=2.303 . R . \Delta \log D / \Delta(1 / T)$, where $R$ is the gas constant. The logarithm plot of the distribution coefficient as function of the reverse of the temperature leads to a straight line (see Figure 3) and the enthalpy can be calculated from the value of the slope of the linear regression that is equal to $-\Delta \mathrm{H}^{\circ} / 2.303 \mathrm{R}$. Therefore, with $\Delta \mathrm{H}^{\circ}=-8$ and $-3.4 \mathrm{~kJ} \cdot \mathrm{mol}^{-1}$ for EBPip-NTf $\mathrm{f}_{2}$ and EOPiP-NTf respectively the extraction process is exothermic, which can describe the reduction in tantalum extraction by increase of the temperature. 




Figure 2 Distribution ratio of Ta as a function of temperature.

Extraction conditions: ILs phase: pure EBPiP-NTf2 or EOPiP-NTf2; Aqueous phase: $[\mathrm{Ta}]=7 \mathrm{~g} / \mathrm{L},\left[\mathrm{H}_{2} \mathrm{SO}_{4}\right]=6 \mathrm{M}$, $[\mathrm{HF}]=1 \mathrm{M}$; $\mathrm{V}_{\mathrm{aq}} / \mathrm{V}_{\mathrm{IL}}=5 ; 1 \mathrm{~h}$ at $20-60^{\circ} \mathrm{C}$.

\section{Temperature $\left({ }^{\circ} \mathrm{C}\right)$}



Figure 3 Logarithm of the distribution ratio $D_{T a}$ as a function of the reverse of the temperature $T$.

Extraction conditions: ILs phase: pure EBPiP-NTf ${ }_{2}$ or EOPiP-NTf ${ }_{2}$; Aqueous phase: $[\mathrm{Ta}]=7 \mathrm{~g} / \mathrm{L},\left[\mathrm{H}_{2} \mathrm{SO}_{4}\right]=6 \mathrm{M},[\mathrm{HF}]=1 \mathrm{M}$; $\mathrm{V}_{\mathrm{aq}} / \mathrm{V}_{\mathrm{IL}}=5$; Temperature $=20^{\circ} \mathrm{C}-60^{\circ} \mathrm{C}$. Extraction time: $1 \mathrm{~h}$. EBPiP-NTf $\log \left(\mathrm{D}_{\mathrm{Ta}}\right)=f(1000 / \mathrm{T}): \mathrm{y}=0.422( \pm 0.011) \mathrm{x}-0.205( \pm 0.035)$; $\mathrm{R}^{2}=0.995 ;$ EOPiP-NTf $2 \log \left(\mathrm{D}_{\mathrm{Ta}}\right)=f(1000 / \mathrm{T}): \mathrm{y}=0.178( \pm 0.004) \mathrm{x}+0.597( \pm 0.014) ; \mathrm{R}^{2}=0.995$ 


\section{Effect of Ta concentration}

Influence of Ta loading on Ta extraction

To determine the loading capacity of Ta that can be extracted by the ILs, a series of experiments was carried out by varying the volume ratio $\mathrm{V}_{\mathrm{aq}} / \mathrm{V}_{\mathrm{IL}}$ and keeping the other conditions constant $\left(6 \mathrm{M} \mathrm{H}_{2} \mathrm{SO}_{4}\right.$, $7 \mathrm{~g} / \mathrm{L} \mathrm{Ta}, 25^{\circ} \mathrm{C}$ ) as illustrated in the Figure 4 . The increase of the volume ratio $\mathrm{V}_{\mathrm{aq}} / \mathrm{V}_{\mathrm{IL}}$ corresponds to an increase of the amount of Ta in contact with the IL phase.

As plotted in Figure 4, the loading capacity of Ta by the EBPiP-NTf 2 phase can be determined as $50 \mathrm{~g} / \mathrm{L}$ that corresponds to the plateau observed for volume ratio $V_{\text {aq }} / V_{\text {IL }}$ value higher to 15.

For the EOPiP-NTf $f_{2}$ phase, the plateau is not observed even with high $\mathrm{Vaq}_{\mathrm{aq}} / \mathrm{V}_{L}$ ratio. The loading capacity which corresponds to the maximum concentration of Ta that the EOPiP-NTf ${ }_{2}$ can contain was estimated to be higher than $100 \mathrm{~g} / \mathrm{L}$.

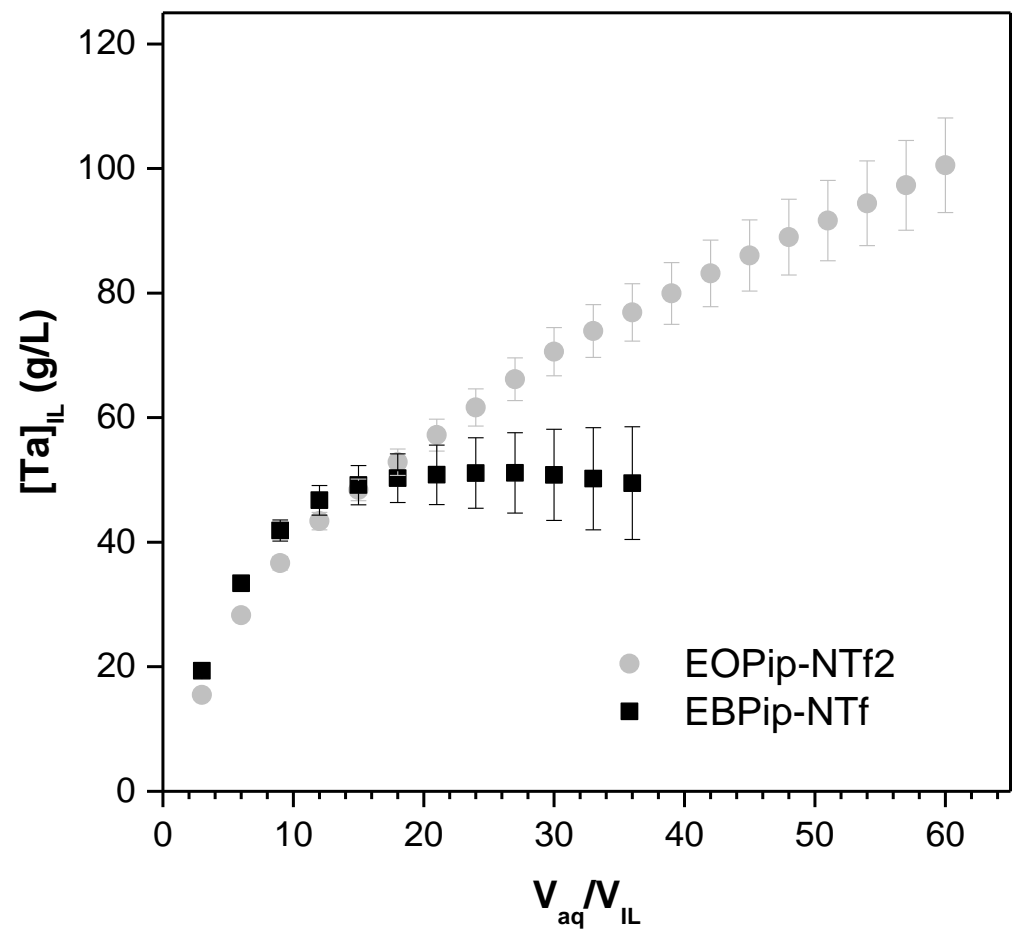

Figure 4. Equilibrium tantalum concentration in EBPiP-NTf $2_{2}$ and EOPiP-NTf 2 ([Ta $]_{\mathrm{LL}}$ eq]) as function of $\mathrm{V}_{\mathrm{aq}} / \mathrm{V}_{\mathrm{IL}}$ ratio. Extraction conditions: IL phase: pure EBPiP-NTf $f_{2}$ or EOPiP-NTf $f_{2}$. Aqueous phase: $[\mathrm{Ta}]=7 \mathrm{~g} / \mathrm{L},\left[\mathrm{H}_{2} \mathrm{SO}_{4}\right]=6 \mathrm{M},[\mathrm{HF}]=1 \mathrm{M} ; 1 \mathrm{~h}$ at $25^{\circ} \mathrm{C}$.

\section{Effect of IL partitioning}

The loss of solvent in the raffinate, as regards to the economic feasibility of the flowsheet, constitutes one of the basic cost elements of the process. In liquid-liquid extraction, loss of solvent can occur by evaporation, chemical attack or solubilization in the aqueous phase.

ILs present some advantageous properties such as low vapor pressure and good thermal stability allowing to overcome evaporation problems. In addition, ${ }^{1} \mathrm{H},{ }^{13} \mathrm{C}$ and ${ }^{19} \mathrm{~F}$ NMR of the IL phase after the extraction experiments indicate that no degradation products are observed indicating the high stability of the IL in strongly acidic media with respect to the detection limits of such analytical tools ( $1 \%$ molar). It has been shown that EBPiP-NTf $f_{2}$ decompose under ultrasonic irradiation in traces of degradation products, ${ }^{32}$ some additional experiments are under investigation in order to study the stability of the EOPiP-NTf 2 . 
The solubility of the ILs in the aqueous phase was estimated by TOC analysis (see Figure 5). Around $0.2 \%$ loss of organic in the pure water is observed while when the initial aqueous phase is acidified and contains Ta, the amount of IL loss increases to less than 1 and $4 \%$ for EOPiP-NTf $f_{2}$ and EBPiP-NTf respectively (Figure 5). By increasing the length of the alkyl chain in the organic cation and therefore the hydrophobicity of the IL cation, the amount of IL transferred in the aqueous phase decreases.

The viscosity decreases after contact with the aqueous phase which can be related to water and acid transferred into the IL phase. After the contact of pure ILs with the feed solution $\left(6 \mathrm{M} \mathrm{H}_{2} \mathrm{SO}_{4}, 7 \mathrm{~g} / \mathrm{L} \mathrm{Ta}\right.$, $25^{\circ} \mathrm{C}, 1 \mathrm{~h}$ ), the viscosity decreases from 284to $208 \mathrm{mPa}$.s and 406 to $329 \mathrm{mPa}$.s respectively for EBPiP$\mathrm{NTf}_{2}$ or EOPiP-NTf $f_{2}$. Karl Fischer and pH-titration of the IL phase were also performed in order to determine the amount of water and acid transferred into the IL phase during the extraction experiment (see Figure S4). As expected, the amount of extracted water depends on the hydrophilicity of the IL cation; indeed a lower concentration of water was measured in EOPipNTf 2 after the contact with water or an acidic aqueous phase. Furthermore, the water amount transferred into the IL phase, for both ILs, increases by decreasing $\mathrm{pH}$. Nevertheless, the acid extraction seems to be independent of the alkyl chain length of the piperidinium part.

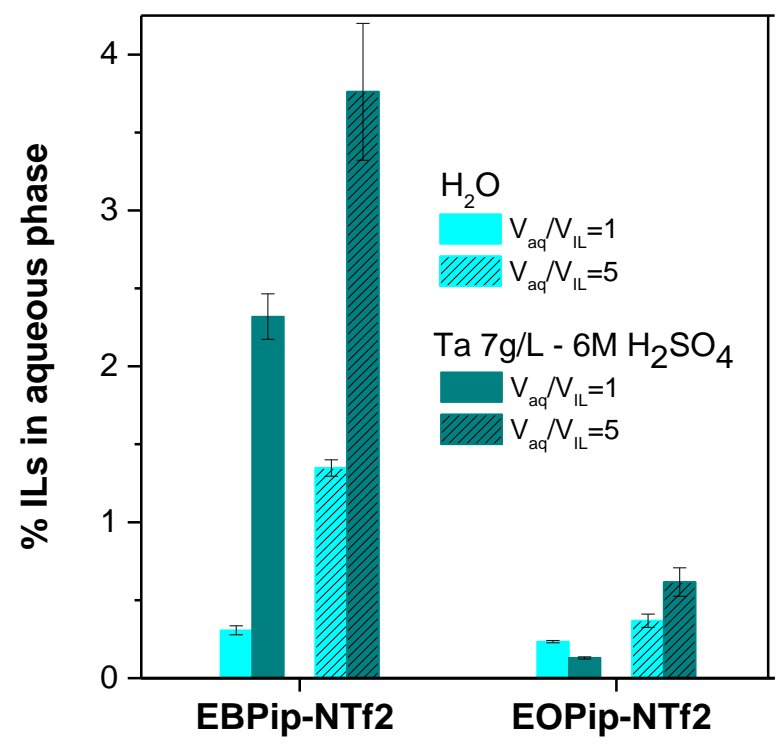

Figure 5. IL percentage loss (\% IL) of EBPiP-NTf ${ }_{2}$ or EOPiP-NTf 2 after contacting with MilliQ water or $6 \mathrm{M} \mathrm{H}_{2} \mathrm{SO}_{4}$ solution containing $7 \mathrm{~g} / \mathrm{L}$ of tantalum and $1 \mathrm{M} \mathrm{HF}$ determined by total organic carbone analysis (TOC). $\mathrm{V}_{\mathrm{aq}} / \mathrm{V}_{\mathrm{IL}}=1$ or $5 ; 1 \mathrm{~h}$ at $25^{\circ} \mathrm{C}$.

\section{Ta extraction from multi-metal-ion solutions}

To consider the selectivity of the ILs to extract Ta, an aqueous multi-element solution was proposed based on the composition determined from an e-wastes leachable slag supplied by TND Company (Quesnoy sur Deule, France).

A simulated leaching solution containing Ta and competitive cations ( $\mathrm{Si}, \mathrm{Sn}, \mathrm{Cu}, \mathrm{Al}, \mathrm{Fe}, \mathrm{Ni}$, and $\mathrm{Cr}$ ) was prepared in $6 \mathrm{M}$ sulfuric acid and contacted with the IL phase. The composition of the solution and the extraction behavior for each metal ion are collected in the Table 2 for EOPiP-NTf $f_{2}$ and for EBPiP-NTf (full detail of initial and equilibrium metal concentration are provided in supporting information, see Table S2). Very close behavior has been observed whatever the alkyl chain length of the considered ILs. The ILs allow a selective extraction of tantalum in regards to the set of competitive ions studied. 
Table 2. Extraction coefficients and selectivity factors $\mathrm{SF}_{\mathrm{Ta} / \mathrm{M}}$ for the multi-element solution. ${ }^{[\mathrm{a}]}$

[a] Extraction conditions: IL phase: pure . Aqueous phase: multi-element solution $\left[\mathrm{H}_{2} \mathrm{SO}_{4}\right]=6 \mathrm{M},[\mathrm{HF}]=0.03 \mathrm{M} ; 1 \mathrm{~h}$ at $25^{\circ} \mathrm{C}$; $\mathrm{V}_{\mathrm{aq}} / \mathrm{V}_{\mathrm{IL}}=5$.

\begin{tabular}{|c|c|c|c|c|c|}
\hline \multirow{2}{*}{ Elements } & \multirow{2}{*}{$\begin{array}{c}\text { Concentration } \\
(\mathrm{mg} / \mathrm{L})\end{array}$} & \multicolumn{2}{|c|}{ EBPip $\left[\mathrm{NTf}_{2}\right]$} & \multicolumn{2}{|c|}{ EOPip $\left[\mathrm{NTf}_{2}\right]$} \\
\hline & & $\mathrm{D}_{\mathrm{M}}$ & $\mathrm{SF}_{\mathrm{Ta} / \mathrm{M}}$ & $\mathrm{D}_{\mathrm{M}}$ & $\mathbf{S F}_{\mathrm{Ta} / \mathrm{M}}$ \\
\hline $\mathrm{Ta}$ & 500 & 21.91 & - & 37.73 & - \\
\hline $\mathrm{Cu}$ & 50 & 0.06 & 365 & 0.13 & 290 \\
\hline Si & 5500 & 0.08 & 274 & 0.15 & 252 \\
\hline Sn & 500 & 0.07 & 322 & 0.16 & 240 \\
\hline $\mathrm{Ni}$ & 20 & 0.10 & 219 & 0.15 & 252 \\
\hline $\mathrm{Cr}$ & 10 & 0.11 & 207 & 0.15 & 260 \\
\hline Al & 25 & 0.07 & 313 & 0.15 & 250 \\
\hline $\mathrm{Fe}$ & 20 & 0.03 & 730 & 0.13 & 295 \\
\hline
\end{tabular}

One of the most interesting result is that, high selectivity of Ta can be achieved using the ILs with separation factor values SF Ta/M greater than 250 even over silicium, which is ten times more concentrated than tantalum.

Nevertheless, EOPiP-NTf $f_{2}$ seems to be the best candidate for Ta extraction from WEEE leachate solution compared to EBPip-NTf 2 . Indeed it allows to extract more Ta with a distribution coefficient higher than 35 and a high selectivity over other metal ions ( $D_{\mathrm{M}} \approx 0.15$, less than $3 \%$ of extraction), and also its solubility into water is lower than the one of EBPip-NTf ${ }_{2}$, reducing solvent loss during extraction and stripping steps.

\section{Reusability studies}

Extraction-Stripping Cycles

The stripping of Tantalum from the IL phase into an aqueous medium is important to recover the metal and consider the recyclability of the IL phase in another extraction cycle.

A series of extraction-stripping has been performed using the same extraction conditions as described above $\left(7 \mathrm{~g} / \mathrm{L} \mathrm{Ta} 6 \mathrm{M} \mathrm{H}_{2} \mathrm{SO}_{4}, \mathrm{~V}_{\mathrm{aq}} / \mathrm{V}_{\mathrm{IL}}\right.$ ratio $\left.=5\right)$ and using pure water as stripping solution $\left(\mathrm{V}_{\mathrm{st}} / \mathrm{V}_{\mathrm{IL}}\right.$ ratio = 2).

The stripped IL phase was then reused for a new extraction experiment under similar experimental conditions (see Figure 6 and Figure S5).

The series of extraction-stripping cycles shows a possible reutilization of used solvent without loss of performance. This can be correlated to the high loading capacity of the IL and to a very low loss of the $\mathrm{IL}$ in the aqueous phase. 


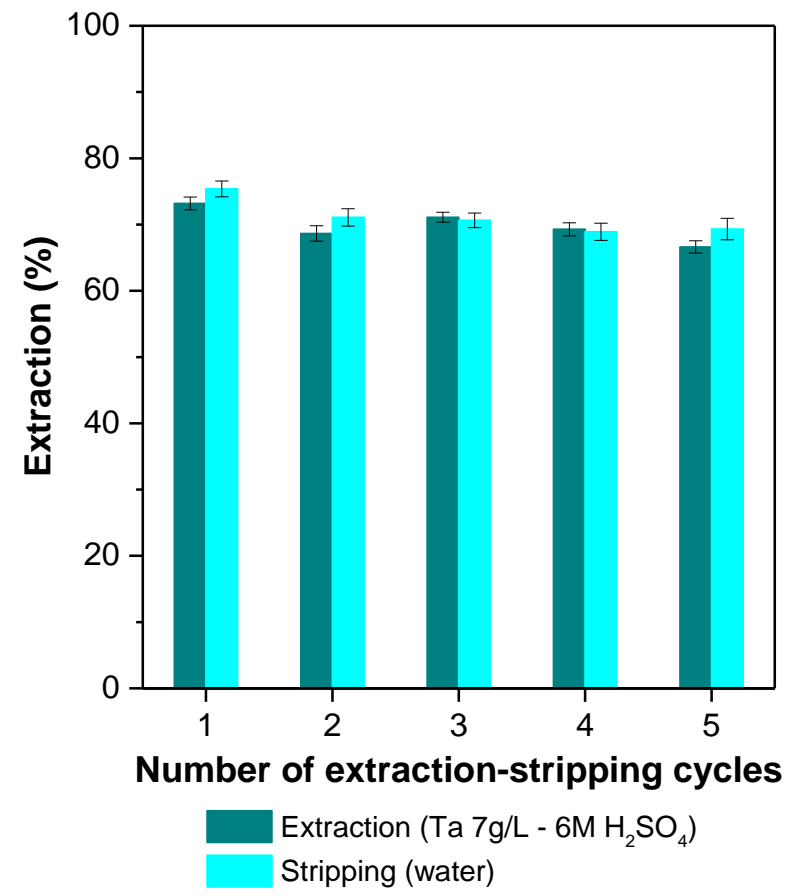

Figure 6. Ta(V) extraction and stripping percentages for EOPip-NTf2 obtained for different number of extraction-stripping cycle. Organic phase: pure EOPip-NTf2 Aqueous phase: $[\mathrm{Ta}]=7 \mathrm{~g} / \mathrm{L},\left[\mathrm{H}_{2} \mathrm{SO}_{4}\right]=6 \mathrm{M},[\mathrm{HF}]=1 \mathrm{M} ; \mathrm{V}_{\mathrm{aq}} / \mathrm{V}_{\mathrm{IL}}=5 ; 1 \mathrm{~h}$ at $25^{\circ} \mathrm{C}$. Stripping: MilliQ water; $\mathrm{V}_{\mathrm{st}} / \mathrm{V}_{\mathrm{IL}}=2 ; 1 \mathrm{~h}$ at $25^{\circ} \mathrm{C}$

\section{Recovery of Ta from the loaded IL phase.}

The stripping of Tantalum from the IL phase into an aqueous medium is a critical stage to the recovery of the metal. It was demonstrated that water is an effective solvent for Tantalum stripping. The stripping efficiency (\%S) can be improved by changing the ratio of the stripping aqueous phase over the loaded IL phase $\left(\mathrm{V}_{\mathrm{St}} / \mathrm{V}_{\mathrm{IL}}\right.$ ratio). An optimum $\mathrm{V}_{\mathrm{St}} / \mathrm{V}_{\mathrm{IL}}$ ratio $=5$ allows the recovery of approximately $95 \%$ of Ta.

By using an excess of ammonium hydroxide solution allowing reaching $\mathrm{pH}$ values of 8 to 9 , a complete precipitation of Ta hydroxides can be achieved. It was previously demonstrated that a molar ratio up to 4 was necessary to perform the quantitative precipitation of tantalum. ${ }^{27}$

The precipitate was then washed two times with distilled water and dried in an oven at $100^{\circ} \mathrm{C}$. The washed and dried precipitate was then calcined at $900^{\circ} \mathrm{C}$ for four hours given a white solid. XRD and SEM-EDS analysis indicates that Tantalum oxide, $\mathrm{Ta}_{2} \mathrm{O}_{5}$, is among the final products obtained after from tantalum stripping solutions following the liquid-liquid extraction processes. ${ }^{33}$. Examination of the diffraction pattern for powders annealed at $900^{\circ} \mathrm{C}$ for 4 hours (Figure 7) indicates that $\mathrm{Ta}_{2} \mathrm{O}_{5}$ was obtained in its orthorhombic $\beta$-phase with characteristic peaks at $2 \theta=22.85,28.77,28.25,36.69$, $46.67,49.75,55.49$ (JCPDS:25-922). ${ }^{34}$ The size of the crystallites was estimated to be around $15 \mathrm{~nm}$ in size.

Considering the full process, the overall yield for the Ta recovery from the initial extraction step to the final oxide obtained after calcination was about $70 \%$ in the more drastic conditions (extraction $\mathrm{V}_{\mathrm{aq}} / \mathrm{V}_{\mathrm{IL}}$ $=5$ and stripping $V_{\text {st }} / V_{\mathrm{IL}}=2$ ). 


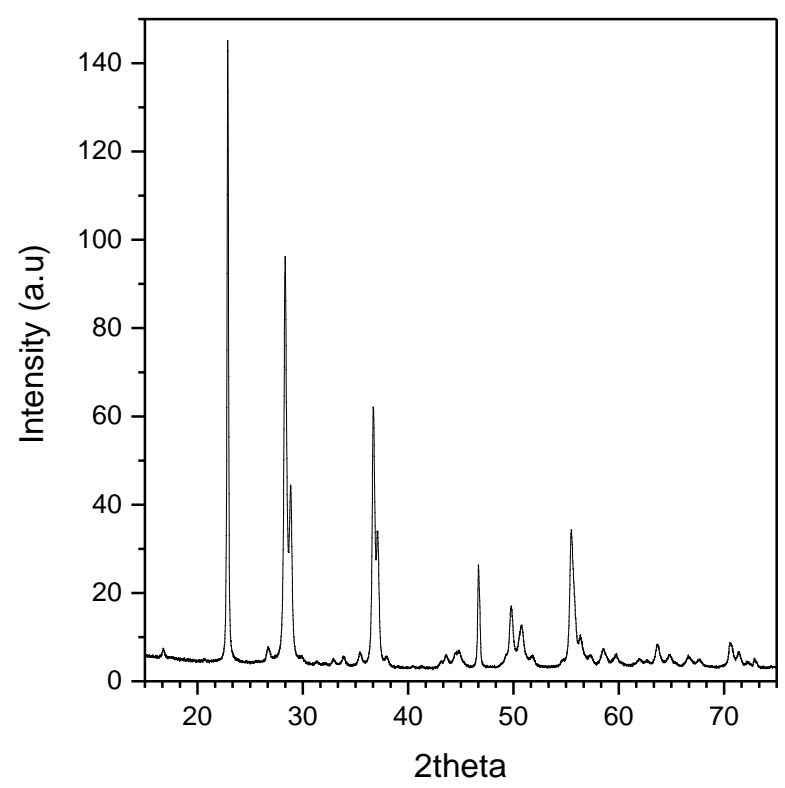

Figure 7. X-ray diffraction pattern of powders obtained after precipitation of the tantalum strip solution and annealed at $900^{\circ} \mathrm{C}$ for 4 hours. $\mathrm{Ta}_{2} \mathrm{O}_{5}$ orthorombic $\beta$-phase (JCPDS: 25-922).

\section{Extraction mechanism analysis}

The extraction of tantalum with MIBK was related to a salting out effect and the species that is responsible for extraction might constitute an ion association complex. ${ }^{35,36}$ In comparison, for the IL based system, different mechanisms may be encountered, such as ion exchange, complexation, neutral coextraction or neutral solvation. ${ }^{37-39}$

As reported in the literature, the extraction efficiency decreases as the hydrophobicity of the IL's cation increases. Accordingly less IL partitions in the aqueous phase, limiting thus the metal ion partitioning. ${ }^{40}$ The present results show that the extraction efficiencies are not dependent on the hydrophobicity of IL cations since performances are not affected when changing from a butyl to an octyl chain, this suggest that the mechanism is not consistent with a cation exchange mechanism. ${ }^{41}$

The amount of IL transferred into the aqueous phase when the initial feeding was only water or a tantalum acidic solution is very close for the EOPiP-NTf ${ }_{2}$. This suggests that this value is probably correlated to the solubilization of EOPiP-NTf in the aqueous phase. For the EBPiP-NTf $f_{2}$, the amount of IL transferred into the aqueous phase increase in the presence of Ta acidic solution; this behavior supports an intrinsic solubilization and loss due to ion exchange.

The recycled IL organic phase exhibits extractive behaviors similar to those of a fresh IL solution, with high extraction efficiencies. This indicates that if an ion-exchange mechanism is involved, it does not have negative effect on the extraction efficiency.

In regard to the different statements and behaviors observed, it appears that the combination of ion pair complex formation and ion-exchange mechanisms could be the driving force of the extraction. No concrete evidence allows the discrimination between these two mechanisms. The possibility of a mixed partitioning mode has already been described in the literature..$^{40,42}$

Depending on the acidity of the medium, one or the other mechanism can be promoted. Several other investigations involving SAXS, EXAFS or computational procedures could help to identify the 
mechanism occurring. These studies could clarify the role of one or the other of the mechanisms and maybe explain the specific selectivity for Ta. ${ }^{43,44}$

\section{Implementation of the process.}

From the different statement obtained in batch mode, experiments have been conducted using centrifuge mixer in a semi-batch mode. One limitation in the use of centrifuge mixer was due to the low difference in density between the IL EOPip-NTf phase (or EBPip-NTf ${ }_{2}$ ) and the $6 \mathrm{M} \mathrm{H}_{2} \mathrm{SO}_{4}$ aqueous feed solution, respectively 1.27 (or 1.37 ) and $1.36 \mathrm{~g} / \mathrm{cm}^{3}$. The study of the density as a function of the acidity of the aqueous phase and the concentration of Ta shows that it is strongly related to the concentration of $\mathrm{H}_{2} \mathrm{SO}_{4}$ and independent of the metal concentration (see Figure $\mathrm{S6}$ ).

Feed solution density can be tuned from $1.07 \mathrm{~g} / \mathrm{cm}^{3}$ to $1.51 \mathrm{~g} / \mathrm{cm}^{3}$ by modifying the $\mathrm{H}_{2} \mathrm{SO}_{4}$ concentration from $1 \mathrm{M}$ to $9 \mathrm{M}$ respectively.

In order to obtain a suitable density difference between the IL phase and the aqueous phase allowing the phase separation in the centrifuge mixer, while keeping a sufficient distribution coefficient (see Figure 1), $\mathrm{H}_{2} \mathrm{SO}_{4}$ concentration was set to $9 \mathrm{M}$.

Experiments where then performed in semi batch mode (see Figure 8 ) by alternatively injecting the heavy phase $\left(9 \mathrm{M} \mathrm{H}_{2} \mathrm{SO}_{4}\right.$ with $7 \mathrm{~g} / \mathrm{L}$ of Ta) and the light phase (IL, EOPip-NTf ${ }_{2}$ or EBPip-NTf 2 ) 5 times (5 cycles of Heavy/light phase injection). Analysis of the aqueous phase (heavy phase) after each injection allowed determining the efficiency of the centrifuge mixer process in term of IL loss and tantalum extraction (see Figure 9 and Figure S7).
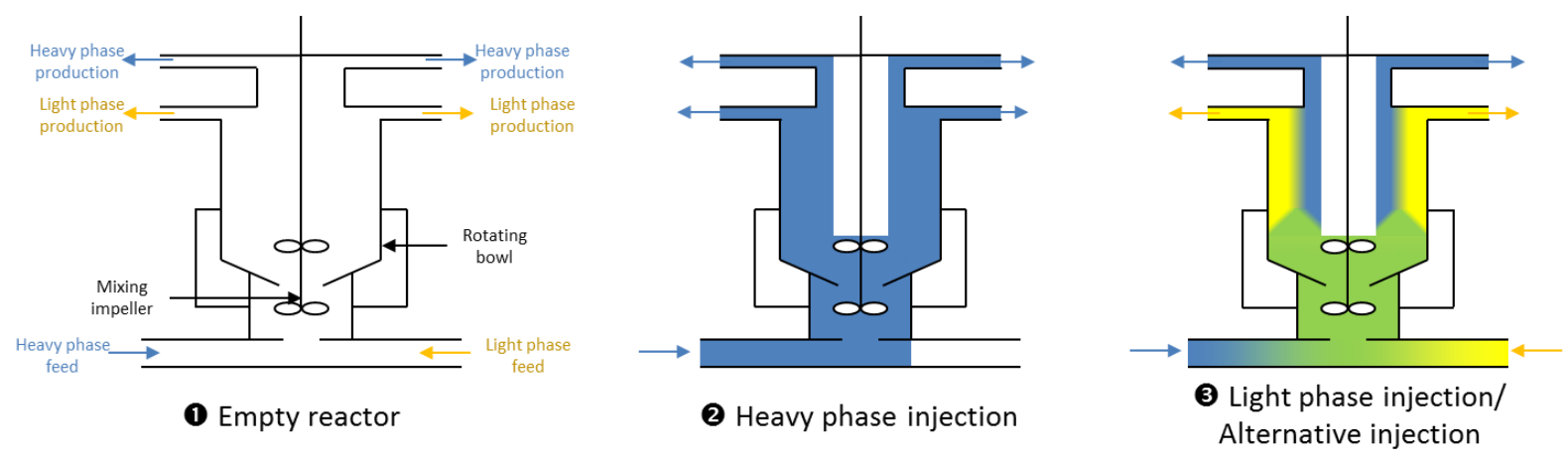

Figure 8. Scheme of the centrifuge mixer reactor at the different stage of the semi batch process: $\mathbf{0}$ empty reactor, 2 heavy phase injection step, and $\mathbf{3}$ light phase injection step and alternative heavy/light injection steps. 

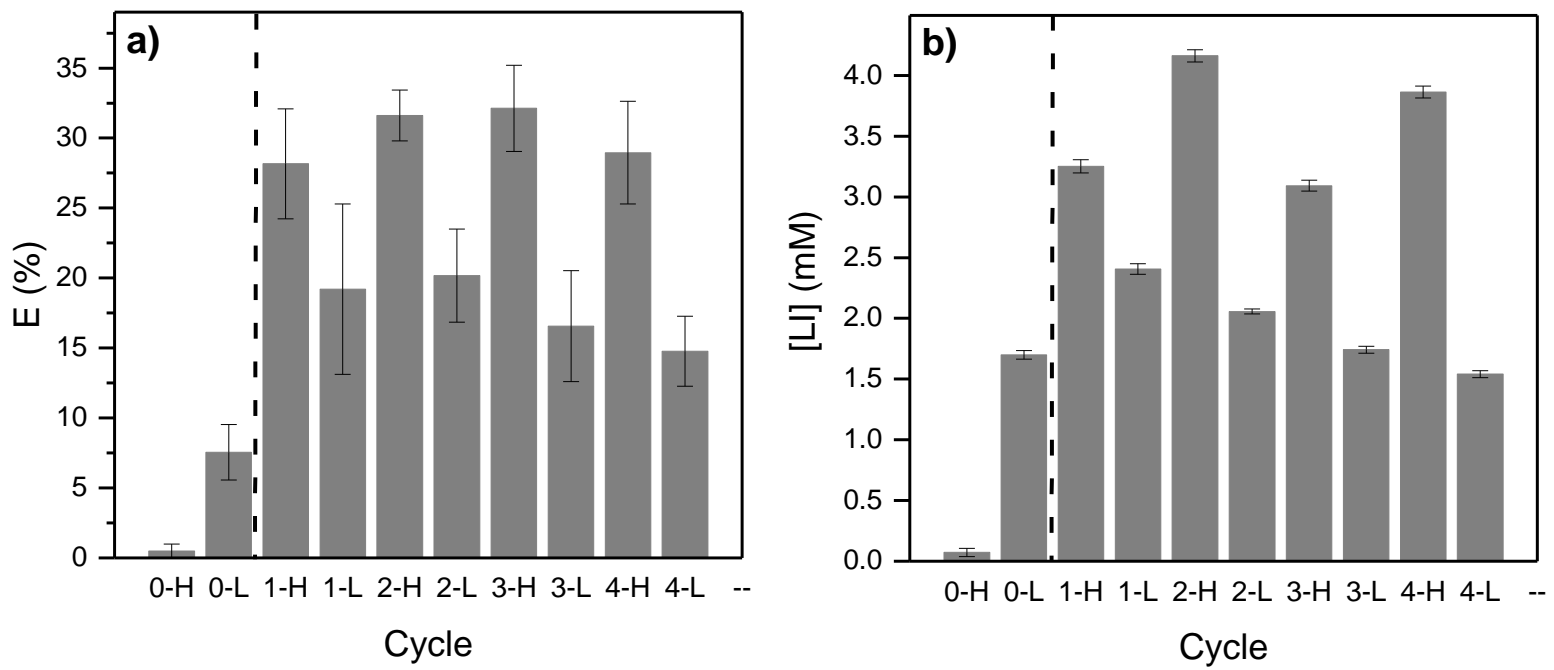

Figure 9. Efficiency of the centrifuge mixing process with EOPip-NTf $f_{2}$ during several alternative heavy $(\mathrm{H}) /$ light $(\mathrm{L})$ injection cycle (0 to 4): a, extraction percent of Ta (Ta concentration ratio between heavy phase production solution and heavy phase feeding solution) and, $\mathrm{b}$, EOPip- $\mathrm{NTf}_{2}$ concentration in the heavy phase production solution. Dot line indicates transition between both regimes.

After a transitory regime corresponding to the filling of the reactor, a stationary regime is observed for both IL. The saw tooth patterns observed is due to the semi batch mode that induced a variation on the volume ratio between each injection step. Ultimately, this semi batch mode allowed recovering around $30 \%$ of Tantalum for each IL in only one stage. IL concentrations of $3 \mathrm{mM}$ and $100 \mathrm{mM}$ for EOPip-NTf $f_{2}$ and EBPip-NTf $f_{2}$ respectively were measured in the production aqueous phase. This demonstrates once again that EOPip-NTf $f_{2}$ is the best candidate for Ta recycling compared to EBPip$\mathrm{NTf}_{2}$ and ketone or phosphonate TSIL. ${ }^{26,27}$

All the results can be rationalized through the flowsheet in Figure 10 that illustrates the full process involving the two main stages allowing tantalum recovery. Also, another possibility for the recovering of tantalum is to consider the IL as electrolyte in order to perform the electrodeposition of the metal. Indeed, the EOPip-NTf ${ }_{2}$ displays interesting electrochemical properties with a wide electrochemical window measured at about $5.3 \mathrm{~V} .{ }^{45}$



Figure 10 Flowsheet for the extraction and recovery of tantalum from sulfuric acid solution. 


\section{Conclusion}

The extraction of Ta from a sulfuric acid phase into an IL phase is effective for EBPiP-NTf ${ }_{2}$ and EOPiP$\mathrm{NTf}_{2}$ ILs. Outstanding extraction parameters such as high efficiency, high loading capacity, and low partitioning in the aqueous feed solution of the EOPiP-NTf $f_{2}$ were highlighted.

Ta extraction efficiency for both ILs is higher than $90 \%$ and is comparable to the one obtained with TSILs bearing a ketone or a phosphonate function when used in the same extraction conditions as described above ( 1 or $7 \mathrm{~g} / \mathrm{L}$ Ta $6 \mathrm{M} \mathrm{H}_{2} \mathrm{SO}_{4}, \mathrm{~V}_{\mathrm{aq}} / \mathrm{V}_{\mathrm{LL}}$ ratio $=1$ ). ${ }^{26,27}$ Nevertheless, the loading capacity of the current ILs is lower than those obtained with the TSIL which is, for the phosphonate TSIL estimated to be higher than $180 \mathrm{~g} / \mathrm{L}^{27}$ that is almost twice as high compared to $100 \mathrm{~g} / \mathrm{L}$ for EOPiP-NTf 2 .

An important aspects to consider in the sustainable design of the process is the loss of ionic liquid in aqueous phase. Taking into account this parameter as a green chemistry argument it appears that ILS systems are more efficient with loss values less than $1 \%$ for the EOPiP-NTf $f_{2}$ compared to $15 \%$ for the TSILs. ${ }^{26,27}$ Therefore considering the efficiency as well as the sustainability of the process the EOPiP$\mathrm{NTf}_{2}$ appear to be greener than the TSILs for similar Ta recovery efficiency.

The solubility of the ionic liquids used is also lower than conventional organic solvents industrially used for Ta extraction such as MIBK. Beyond the lower solubility such system will has a limited impact on health and atmospheric environment due to it quasi non flammability and non volatility in comparison to MIBK which is a highly flammable liquid.

Also, the IL is selective to tantalum with respect to all other cations considered in the simulated solution of an e-waste leachable slag, with separation factors higher than 250 . The two main impurities ( $\mathrm{Si}$ and $\mathrm{Sn}$ ) are almost not extracted. Beyond the use of this system for the treatment of e-waste, it also is efficient for the treatment of ores by acidic leaching liquors for the separation of Ta from $\mathrm{Nb}^{46}$

As shown with the extraction-stripping cycles, the recycled IL phase exhibits the same extractive behaviors as the initial IL phase, allowing to seriously consider the recyclability of the IL phase. The recovery of the Ta in its oxide form is easily performed after the stripping using water followed by a precipitation step with ammonia and thermal treatment. We showed that the use of EOPiP-NTf ${ }_{2}$ as extraction media allows the setting of an "eco-friendly" process for extraction and recovery of Ta. Even if metal mining has significant economical benefits as it has been shown to cause persistent environmental devastations. Ta recycling from end-of-life products can reduce the environmental footprint by reducing the need for primary raw materials. The implementation of the process at pilot scale on a real leachate from a slag from e-waste is under consideration. The feasibility for the electrodeposition of Ta using such system is also planned.

\section{Associated content}

Supporting Information: additional data on extraction behavior and physicochemical properties of IL based system (Table S1, TableS2 and Figure S1 to Figure S7).

\section{Acknowledgements}

The authors acknowledge B. Baus-Lagarde for conducting ICP/MS experiments. The authors thank the Agence Nationale de la Recherche through the SILEXE project (ANR-13-CDII-0010), the Labex Project CheMISyst (ANR-10-LABX-05-01), the SATT AXLR for financial support and TND Company.

\section{Reference}


1. Study on the review of the list of Critical Raw Materials; European Commission: 2017, $10.2873 / 876644$.

2. K. Mensah, A.; O. Mahiri, I.; Owusu, O.; D. Mireku, O.; Wireko, I.; A. Kissi, E., Environmental Impacts of Mining: A Study of Mining Communities in Ghana. Applied Ecology and Environmental Sciences 2019, 3 (3), 81-94, 10.12691/aees-3-3-3.

3. Birat, J.-P., Life-cycle assessment, resource efficiency and recycling. Metall. Res. Technol. 2015, 112 (2), 206, 10.1051/metal/2015009.

4. Kiddee, P.; Naidu, R.; Wong, M. H., Electronic waste management approaches: An overview. Waste Management 2013, 33 (5), 1237-1250, 10.1016/j.wasman.2013.01.006.

5. Tanskanen, P., Management and recycling of electronic waste. Acta Materialia 2013, 61 (3), 1001-1011, 10.1016/j.actamat.2012.11.005.

6. Sun, Z.; Xiao, Y.; Agterhuis, H.; Sietsma, J.; Yang, Y., Recycling of metals from urban mines - a strategic evaluation. J. Cleaner Prod. 2016, 112, 2977-2987, 10.1016/j.jclepro.2015.10.116.

7. Cucchiella, F.; D'Adamo, I.; Lenny Koh, S. C.; Rosa, P., Recycling of WEEEs: An economic assessment of present and future e-waste streams. Renewable Sustainable Energy Rev. 2015, 51, 263-272, 10.1016/j.rser.2015.06.010.

8. Cui, J.; Zhang, L., Metallurgical recovery of metals from electronic waste: A review. J. Hazard. Mater. 2008, 158 (2), 228-256, 10.1016/j.jhazmat.2008.02.001.

9. Das, A.; Vidyadhar, A.; Mehrotra, S. P., A novel flowsheet for the recovery of metal values from waste printed circuit boards. Resour., Conserv. Recycl. 2009, 53 (8), 464-469, 10.1016/j.resconrec.2009.03.008.

10. Guo, J.; Guo, J.; Xu, Z., Recycling of non-metallic fractions from waste printed circuit boards: A review. J. Hazard. Mater. 2009, 168 (2), 567-590, 10.1016/j.jhazmat.2009.02.104.

11. Wang, X.; Gaustad, G., Prioritizing material recovery for end-of-life printed circuit boards. Waste Management 2012, 32 (10), 1903-1913, 10.1016/j.wasman.2012.05.005.

12. Chancerel, P.; Rotter, V. S.; Ueberschaar, M.; Marwede, M.; Nissen, N. F.; Lang, K.-D., Data availability and the need for research to localize, quantify and recycle critical metals in information technology, telecommunication and consumer equipment. Waste Manage. Res. 2013, 31 (10), 3-16, 10.1177/0734242×13499814.

13. Mineta, K.; Okabe, T. H., Development of a recycling process for tantalum from capacitor scraps. J. Phys. Chem. Solids 2005, 66 (2), 318-321, 10.1016/j.jpcs.2004.06.060.

14. Mackay, D. A. R.; Simandl, G. J., Geology, market and supply chain of niobium and tantaluma review. Miner. Deposita 2014, 49 (8), 1025-1047, 10.1007/s00126-014-0551-2.

15. Reuter, M. A.; Hudson, C.; van Schaik, A.; Heiskanen, K.; Meskers, C.; Hagelüken, C., Metal Recycling: Opportunities, Limits, Infrastructure, A Report of the Working Group on the Global Metal Flows to the International Resource Panel. United Nations Environment Programme: 2013,

20.500.11822/8850.

16. Rotter, V.; Chancerel, P.; Ueberschaar, M. In Recycling oriented product characterization for electric and electronic equipment as a tool to enable recycling of critical metals, REWAS 2013:

Enabling Materials Resource Sustainability, San Antonio, Texas, USA, 3-7 March 2013; Kvithyld, A.; Meskers, C., Eds. John Wiley \& Sons: San Antonio, Texas, USA, 2013; pp 192-201,

17. Ueberschaar, M.; Dariusch Jalalpoor, D.; Korf, N.; Rotter, V. S., Potentials and Barriers for Tantalum Recovery from Waste Electric and Electronic Equipment. J. Ind. Ecol. 2017, 21 (3), 700-714, 10.1111/jiec.12577.

18. Zhu, Z.; Cheng, C. Y., Solvent extraction technology for the separation and purification of niobium and tantalum: A review. Hydrometallurgy 2011, 107 (1), 1-12,

10.1016/j.hydromet.2010.12.015.

19. Brennecke, J. F.; Maginn, E. J., lonic liquids: Innovative fluids for chemical processing. AlChE J. 2001, 47 (11), 2384-2389, 10.1002/aic.690471102.

20. Visser, A. E.; Swatloski, R. P.; Reichert, W. M.; Mayton, R.; Sheff, S.; Wierzbicki, A.; Davis, J. J. H.; Rogers, R. D., Task-specific ionic liquids for the extraction of metal ions from aqueous solutions.

Chem. Commun. 2001, (1), 135-136, 10.1039/B008041L. 
21. Rout, A.; Binnemans, K., Liquid-liquid extraction of europium(iii) and other trivalent rareearth ions using a non-fluorinated functionalized ionic liquid. Dalton Trans. 2014, 43 (4), 1862-1872, 10.1039/C3DT52285G.

22. Sun, X.; Waters, K. E., Development of Industrial Extractants into Functional lonic Liquids for Environmentally Friendly Rare Earth Separation. ACS Sustainable Chem. Eng. 2014, 2 (7), 1910-1917, $10.1021 /$ sc500255n.

23. Chen, Y.; Wang, H.; Pei, Y.; Ren, J.; Wang, J., pH-Controlled Selective Separation of Neodymium (III) and Samarium (III) from Transition Metals with Carboxyl-Functionalized lonic Liquids. ACS Sustainable Chem. Eng. 2015, 3 (12), 3167-3174, 10.1021/acssuschemeng.5b00742. 24. Dupont, D.; Binnemans, K., Rare-earth recycling using a functionalized ionic liquid for the selective dissolution and revalorization of Y2O3:Eu3+ from lamp phosphor waste. Green Chem. 2015, 17 (2), 856-868, 10.1039/C4GC02107J.

25. Spitczok von Brisinski, L.; Goldmann, D.; Endres, F., Recovery of Metals from Tantalum Capacitors with lonic Liquids. Chem. Ing. Tech. 2014, 86 (1-2), 196-199, 10.1002/cite.201300059. 26. Turgis, R.; Arrachart, G.; Michel, S.; Legeai, S.; Lejeune, M.; Draye, M.; Pellet-Rostaing, S., Ketone functionalized task specific ionic liquids for selective tantalum extraction. Sep. Purif. Technol. 2018, 196, 174-182, 10.1016/j.seppur.2017.08.009.

27. Micheau, C.; Lejeune, M.; Arrachart, G.; Draye, M.; Turgis, R.; Michel, S.; Legeai, S.; PelletRostaing, S., Recovery of tantalum from synthetic sulfuric leach solutions by solvent extraction with phosphonate functionalized ionic liquids. Hydrometallurgy 2019, 189, 105107, 10.1016/j.hydromet.2019.105107.

28. Chatel, G.; Goux-Henry, C.; Mirabaud, A.; Rossi, T.; Kardos, N.; Andrioletti, B.; Draye, M., $\mathrm{H} 2 \mathrm{O} 2 / \mathrm{NaHCO} 3-m e d i a t e d$ enantioselective epoxidation of olefins in NTf2-based ionic liquids and under ultrasound. J. Catal. 2012, 291, 127-132, 10.1016/j.jcat.2012.04.016.

29. Dietz, M. L.; Stepinski, D. C., A ternary mechanism for the facilitated transfer of metal ions into room-temperature ionic liquids (RTILs): implications for the "greenness" of RTILs as extraction solvents. Green Chem. 2005, 7 (10), 747-750, 10.1039/b508604c.

30. Dietz, M. L.; Stepinski, D. C., Anion concentration-dependent partitioning mechanism in the extraction of uranium into room-temperature ionic liquids. Talanta 2008, 75 (2), 598-603, 10.1016/j.talanta.2007.11.051.

31. Visser, A. E.; Swatloski, R. P.; Reichert, W. M.; Griffin, S. T.; Rogers, R. D., Traditional extractants in nontraditional solvents: Groups 1 and 2 extraction by crown ethers in roomtemperature ionic liquids. Ind. Eng. Chem. Res. 2000, 39 (10), 3596-3604, 10.1021/ie000426m.

32. Chatel, G.; Pflieger, R.; Naffrechoux, E.; Nikitenko, S. I.; Suptil, J.; Goux-Henry, C.; Kardos, N.; Andrioletti, B.; Draye, M., Hydrophobic Bis(trifluoromethylsulfonyl)imide-Based lonic Liquids Pyrolysis: Through the Window of the Ultrasonic Reactor. ACS Sustainable Chem. Eng. 2013, 1 (1), 137-143, 10.1021/sc300068d.

33. Agulyansky, A.; Agulyansky, L.; Travkin, V. F., Liquid-liquid extraction of tantalum with 2octanol. Chem. Eng. Process. 2004, 43 (10), 1231-1237, 10.1016/j.cep.2003.11.008.

34. Roth, R. S.; Waring, J. L.; Parker, H. S., Effect of oxide additions on the polymorphism of tantalum pentoxide. IV. The system Ta2O5 •Ta2W08. J. Solid State Chem. 1970, 2 (3), 445-461, 10.1016/0022-4596(70)90104-0.

35. Gupta, C. K., Extractive metallurgy of niobium, tantalum, and vanadium. International Metals Reviews 1984, 29 (1), 405-444, 10.1179/imtr.1984.29.1.405.

36. Yang, X.; Wang, X.; Wei, C.; Zheng, S.; Zhang, Y., Low-Acid Extraction of Tantalum from a Tantalum-Niobium Pulp by MIBK. Solvent Extraction Research and Development, Japan 2013, 20, 159-168, 10.15261/serdj.20.159.

37. Billard, I.; Ouadi, A.; Gaillard, C., Is a universal model to describe liquid-liquid extraction of cations by use of ionic liquids in reach? Dalton Trans. 2013, 42 (17), 6203-6212, 10.1039/C3DT32159B. 
38. Janssen, C. H. C.; Macías-Ruvalcaba, N. A.; Aguilar-Martínez, M.; Kobrak, M. N., Metal extraction to ionic liquids: the relationship between structure, mechanism and application. Int. Rev. Phys. Chem. 2015, 34 (4), 591-622, 10.1080/0144235X.2015.1088217.

39. Turgis, R.; Arrachart, G.; Dubois, V.; Dourdain, S.; Virieux, D.; Michel, S.; Legeai, S.; Lejeune, M.; Draye, M.; Pellet-Rostaing, S., Performances and mechanistic investigations of a triphosphine trioxide/ionic liquid system for rare earth extraction. Dalton Trans. 2016, 45 (3), 1259-1268, 10.1039/C5DT03072B.

40. Dietz, M. L.; Dzielawa, J. A.; Laszak, I.; Young, B. A.; Jensen, M. P., Influence of solvent structural variations on the mechanism of facilitated ion transfer into room-temperature ionic liquids. Green Chem. 2003, 5 (6), 682-685, 10.1039/B310507P.

41. Sun, X.; Luo, H.; Dai, S., Mechanistic investigation of solvent extraction based on anionfunctionalized ionic liquids for selective separation of rare-earth ions. Dalton Trans. 2013, 42 (23), 8270-8275, 10.1039/C3DT50148E.

42. Wehbie, M.; Arrachart, G.; Ghannam, L.; Karamé, I.; Pellet-Rostaing, S., An ionic liquid-based extraction system using diglycolamide functionalized macrocyclic platforms for the extraction and recovery of lanthanides. Dalton Trans. 2017, 46 (47), 16505-16515, 10.1039/C7DT02797D.

43. Gaillard, C.; Mazan, V.; Georg, S.; Klimchuk, O.; Sypula, M.; Billard, I.; Schurhammer, R.; Wipff, G., Acid extraction to a hydrophobic ionic liquid: the role of added tributylphosphate investigated by experiments and simulations. Phys. Chem. Chem. Phys. 2012, 14 (15), 5187-5199, 10.1039/C2CP40129K.

44. Sukhbaatar, T.; Dourdain, S.; Turgis, R.; Rey, J.; Arrachart, G.; Pellet-Rostaing, S., lonic liquids as diluents in solvent extraction: first evidence of supramolecular aggregation of a couple of extractant molecules. Chem. Commun. 2015, 51 (88), 15960-15963, 10.1039/c5cc06422h.

45. Traore, Y.; Legeai, S.; Diliberto, S.; Arrachart, G.; Pellet-Rostaing, S.; Draye, M., New insight into indium electrochemistry in a Tf2N-based room-temperature ionic liquid. Electrochim. Acta 2011, 58, 532-540, 10.1016/j.electacta.2011.09.085.

46. Turgis, R.; Arrachart, G.; Pellet-Rostaing, S.; Draye, M.; Legeai, S.; Virieux, D.; Thomas, C. Processes for extracting and recovering tantalum from acid aqueous phase by an ionic liquid. WO2017025547A1, 2017. 


\section{For Table of Contents Use Only}



\section{Synopsis}

This work investigates the use of ionic liquids for the development of environmentally friendly recovery of tantalum. 